\title{
BLIMP1a, the master regulator of plasma cell differentiation is a tumor supressor gene in B cell lymphomas
}

\author{
Katerina Vrzalikova ${ }^{\mathrm{a}, \mathrm{b}}$, Ciaran Bernard John Woodman ${ }^{\mathrm{a}}$, Paul Gerard Murray ${ }^{\mathrm{a}, \mathrm{b}}$
}

\begin{abstract}
Aims. The aim of this review was to summarize recent knowledge of the structure and function of a transcriptional repressor, B lymphocyte induced maturation protein 1 (BLIMP1) and its participation in the pathogenesis of B lymphomas. Methods and results. This review summarizes the structure and function of BLIMP1, its major target genes and its role as a tumour suppressor in B cell lymphomas. We review our recent data implicating the loss of BLIMP1a as an important step in the pathogenesis of the Epstein-Barr virus (EBV) associated B cell lymphomas.

Conclusions. BLIMP1 is a transcriptional repressor essential for the differentiation of germinal centre (GC) B cells to plasma cells. The loss of BLIMP1 in GC B cells could contribute to the pathogenesis of EBV-associated lymphomas by preventing plasma cell differentiation and viral replication.
\end{abstract}

Key words: BLIMP1, Epstein-Barr virus, DLBCL, review

Received: August 29, 2011; Accepted: January 3, 2012; Available online: January 31, 2012

http://dx.doi.org/10.5507/bp.2012.003

aSchool of Cancer Sciences, University of Birmingham, Birmingham, United Kingdom

${ }^{b}$ Department of Clinical and Molecular Pathology and Institute of Molecular and Translation Medicine, Faculty of Medicine and

Dentistry, Palacky University Olomouc, Czech Republic

Corresponding author: Katerina Vrzalikova, e-mail: k.vrzalikova@bham.ac.uk

\section{INTRODUCTION}

BLIMP1 is a transcriptional repressor encoded by the PRDM1 gene and is often described as the 'master regulator' of plasma cell differentiation. BLIMP1 was originally identified as a silencer of the human $\beta$-interferon gene 1 that bound to the positive regulatory domain I (PRDI) of the $\beta$-interferon promoter and was therefore designated 'positive regulatory domain I-binding factor 1' (PRDIBF1). Davis et al. isolated a murine cDNA that was induced following the cytokine-dependent differentiation of the mouse lymphoma cell line, BCL1, and named this, B lymphocyte induced maturation protein 1 (BLIMP1) (ref. ${ }^{2,3}$ ). The same group also demonstrated that ectopically expressed BLIMP1 was sufficient to drive plasma cell differentiation in BCL1 cells2. Definitive proof of the indispensable role of BLIMP1 in plasma cell differentiation and Ig secretion was provided by the Calame group using a conditional knock-out of BLIMP1 in mice4.

\section{GENE ORGANIZATION AND PROTEIN DOMAINS OF BLIMP1}

The human PRDMI gene is located on chromosome 6q21-q22.1 (ref. ${ }^{5}$ ) and encodes two major isoforms, designated BLIMP $1 \alpha$ and BLIMP $1 \beta$, which arise from alternate promoters ${ }^{6}$. The full-length BLIMP $1 \alpha$ protein is responsible for plasma cell differentiation ${ }^{4,7}$. In contrast, BLIMP $1 \beta$ is transcribed from a novel promoter and new exon, $1 \beta$, located upstream of exon 4 of the full-length gene $^{6}$ (Fig. 1). The BLIMP $1 \beta$ protein lacks the first 101 amino acids of BLIMP $1 \alpha$ and instead contains 3 novel amino acids fused to amino acids 102-789 of BLIMP1 $\alpha$. Since BLIMP $1 \beta$ contains the DNA-binding domain but bears a disrupted regulatory domain, it has been suggested that it might inhibit BLIMP $1 \alpha$ functions ${ }^{6}$. In normal B cells, BLIMP1 $\beta$ mRNA levels are substantially lower relative to the full-length form ${ }^{6}$.

In mice, alternative splicing of exon 7 of $P R D M I$ leads to production of the BLIMP $1 \Delta 7$ protein which lacks the first 3 zinc fingers and is therefore predicted to be nonfunctional ${ }^{8}$. Despite having impaired DNA binding activity, the BLIMP $1 \Delta 7$ form was shown to negatively regulate proliferation and cell survival when expressed in an immature B cell line and to interfere with the activity of fulllength BLIMP $1 \alpha$, presumably by forming non-functional heterodimers ${ }^{9}$. The BLIMP $1 \Delta 7$ isoform is preferentially expressed in naïve $B$ cells where it might regulate the levels of BLIMP $1 \alpha$ (ref. $\left.^{9}\right)$. A similar alternatively spliced form of the human protein was described (BLIMP1 $\Delta 6$ ) $\left(\right.$ ref. $\left.^{10}\right)$.

BLIMP1 protein has a PR domain, so-called after it was identified in both the BLIMP1 (PRDIBF1) and the $\mathbf{R b}$-binding protein RIZ1 proteins ${ }^{1,11}$ (Fig. 2). The PR domain is a subclass of the SET domain of histone methyl transferases (HMT) (ref. ${ }^{12}$ ). BLIMP1 also contains five Krüppel-type zinc finger DNA-binding domains located near its C-terminus; however, only the first two finger motifs appear to be required for binding to target loci ${ }^{13}$. The consensus-binding site for BLIMP1, the PRDI site, is an 11-bp sequence (A/C)AG(T/C)GAAAG(T/C) $(\mathrm{G} / \mathrm{T})$ and is similar to the binding sites for IFN regulatory factor (IRF) 1 and IRF2 $\left(\mathrm{ref}^{14}\right)$. BLIMP1 further contains a proline-rich region and two acidic regions (one each at the $\mathrm{N}$ and $\mathrm{C}$ termini). The proline-rich region and the 
first two zinc fingers of BLIMP1 are required for transcriptional repression.

\section{MECHANISMS OF BLIMP1-MEDIATED REPRESSION OF TARGET GENES}

BLIMP1 uses different mechanisms to silence its target genes in a context-dependent manner. Individual domains of the BLIMP1 protein recruit specific co-repressor complexes or chromatin modifying enzymes to mediate transcriptional repression.

The proline-rich region and the zinc finger domains are involved in the recruitment of transcriptional corepressors of the Groucho family ${ }^{15}$. BLIMP1 complexes with the G9a histone methyltransferase through the first 2 zinc fingers resulting in methylation of lysine 9 on histone $\mathrm{H} 3$ (H3K9) and repression of the interferon- $\beta$ promoter ${ }^{16}$. The proline-rich region and the zinc finger domains also interact with histone deacetylases (HDAC)s 1/2 to deacetylate histone $\mathrm{H} 3$ ( ref. $^{17}$ ) as well as with a lysine-specific demethylase, LSD1 ( $\left.\mathrm{ref}^{18}\right)$, that demethylates mono- or di-methyl groups on $\mathrm{H} 3 \mathrm{~K} 4$ ( ref. $^{19}$ ). It has been proposed that recruitment of HDACs $1 / 2$ and LSD 1 is a prerequisite for $\mathrm{H} 3 \mathrm{~K} 9$ methylation and for the silencing of mature B cell gene expression program during plasma cell differentiation ${ }^{18}$. Thus, BLIMP1 serves as a scaffold to recruit proteins or co-repressor complexes that modify histones (by deacetylation, $\mathrm{H} 3 \mathrm{~K} 9$ methylation, and arginine methylation) and in doing so assembles silent chromatin over the target loci. However, it remains to be determined how exactly chromatin is modified at specific BLIMP1 target genes and whether chromatin modification is the only mechanism by which BLIMP1 represses transcription.

\section{BLIMP1 IS REQUIRED FOR PLASMA CELL DIFFERENTIATION}

BLIMP1 expression is essential and sufficient for plasma cell differentiation ${ }^{4,20}$. The first indication of the importance of BLIMP1 in plasma cell differentiation was provided by the demonstration that ectopic expression of BLIMP1 in mouse B cell lines or in mouse primary splenocytes promoted a plasma cell-like phenotype ${ }^{2,21}$. Knockout mice with a conditional deletion in mature B cells of all five zinc finger domains of BLIMP1, showed normal B cell development and number ${ }^{4}$. However, following challenge with both T-independent and T-dependent antigens, these mice showed a virtual absence of plasma cells and diminished immunoglobulin (Ig) secretion. Moreover, mice lacking BLIMP1 in the B cell lineage generated normal numbers of peripheral B cell subsets which were capable of self-renewal, but in which the secretion of all Ig isotypes was severely reduced. Germinal centres (GC) $\mathrm{s}$ in these mice were enlarged, suggesting a developmental block at the late/post-GC stages ${ }^{20}$.

The initial step of plasma cell differentiation is BLIMP1-independent and occurs as a result of the func- tional inactivation of paired box gene 5 (PAX5) in mature B cells by a so far unidentified stimulus ${ }^{22}$. PAX 5 is a transcription factor that is essential for the commitment of lymphoid progenitors to the B cell lineage and for the maintenance of 'B-cell identity' ( ref. $^{23}$ ). The experimentally induced down-regulation of PAX5 in mature B cells results in the establishment of a 'pre-plasmablast' stage characterised by the secretion of low amounts of antibodies $^{22}$. The production of antibodies is mediated by the induction and splicing of X-box binding protein 1 (XBP1), which activates multiple genes which regulate Ig production, the ER stress response (the unfolded protein response), changes in cell size and protein synthesis ${ }^{24-26}$. The induction of BLIMP1 in pre-plasmablasts is necessary to stabilize and maintain the plasma cell differentiation program ${ }^{4,22}$. Pre-plasmablasts are precursors of immature short-lived plasma cells, known as plasmablasts which have intermediate levels of BLIMP1, express Igs, and have a high rate of proliferation ${ }^{27}$ and apoptosis ${ }^{28}$. Expression of interferon regulatory factor 4 (IRF4), another transcriptional factor essential for plasma cell differentiation, is induced in plasmablasts in response to NF- $\kappa$ B-mediated CD40 signalling or calcium-dependent activation of nuclear factor of activated T cells (NFAT) transcription factors ${ }^{29-34}$. The differentiation of plasmablasts to long-lived, post-mitotic plasma cells producing large amounts of antibodies is associated with a further increase in BLIMP1 expression ${ }^{27}$.

\section{BLIMP1 TARGET GENES}

BLIMP1 target genes have been identified in transformed human B cell lines ${ }^{35}$ and in murine M12 cells ${ }^{36}$ following their transfection with BLIMP1; and in BCL1 cells following their cytokine-induced differentiation ${ }^{36}$.

\section{BLIMP1 TARGET GENES CONTROLLING MATURE B CELL FUNCTIONS AND AFFINITY MATURATION}

BLIMP1 silences genes which specify B cell identity, these include: surface B cell markers (CD19, $C D 20, C D 22, C D 45)$; B cell activation markers (CD69, $M I P-1 \beta, A 1)$; B cell-associated transcription factors (BCL6, PAX5, SPIB, OCT-2, STAT6, EBF); BCR signalling components (BLNK, CD79A, SYK, BTK, PKC , $L Y N)$; and, genes induced by BCR signalling ( $A 1, M I P$ $1 \beta$, CD69, CD83, and SPI-1/PU.1) (ref. ${ }^{35}$ ). BLIMP1 also inhibits class switch recombination (CSR) by silencing genes essential for CSR and/or somatic hypermutation (SHM) (e.g. KU70, KU86, DNA-PKCS and AID) (ref. ${ }^{37-39,35}$ ). CIITA is also repressed by BLIMP1 (ref. ${ }^{40,35}$ ), which leads to the down-regulation of MHC class II genes and antigen presentation in plasma cells ${ }^{41}$. 


\section{BLIMP1 TARGET GENES CONTROLLING CELL CYCLE AND APOPTOSIS}

BLIMP1 also down-regulates genes involved in cell proliferation, partly by directly repressing $C-M Y C$ expression $^{35,42}$. Accordingly, many C-MYC target genes are also regulated by BLIMP1 (e.g. $R C L, O D C, L D H-A$, and $D H F R$ ) (ref. ${ }^{35,43,44}$ ). BLIMP1 also down-regulates genes involved in DNA synthesis and repair (PCNA, PMS4, KU70, KU86, $M C M 2$, primase) and cell cycle progression (PLK, aurora kinase, CKSHS1, CKSHS2, CDC2, CDK2, E2F-1), perhaps as an indirect consequence of the cell cycle arrest due to the loss of C-MYC (ref. ${ }^{35}$ ). Although the repression of $C-M Y C$ transcription is necessary for the exit of B cells from the cell cycle and terminal differentiation of B cells, the removal of C-MYC activity is not sufficient to trigger plasma cell differentiation ${ }^{45}$.

The expression of BLIMP1 in B cell lymphomas representative of immature or partially activated B cells induces cell cycle arrest and apoptosis, in part by repressing the expression of C-MYC and of the anti-apoptotic BCL2 family member A1 (BCL2A1). In contrast, in fully activated $\mathrm{B}$ cells BLIMP1 expression promotes differentiation ${ }^{28,46}$. This has led to suggestion that BLIMP1 expression induces growth arrest and cell death at earlier stages of B cell development but promotes maturation and Ig secretion at later stages of $\mathrm{B}$ cell differentiation.

\section{BLIMP1 TARGET GENES CONTROLLING IMMUNOGLOBULIN SECRETION AND PLASMA CELL FUNCTIONS}

BLIMP1 activates genes involved in antibody production and the stress response ${ }^{35}$. This induction is in part mediated by the inactivation of PAX5 and derepression of down-stream targets of PAX5 including XBPI (ref. ${ }^{24,36,47}$ ), $J$ chain $^{48}$ and $I g H$ chain gene ${ }^{49}$. Accordingly, BLIMP1-expressing cells exhibit a dramatic increase in both total $I g$ mRNA as well as individual $I g$ mRNA isoforms ${ }^{36}$. BLIMP1 also up-regulates the expression of $C X C R 4$ and the integrin receptor VLA4 (ref. ${ }^{36}$ ), both of which have been shown to participate in the migration of plasma cells to specialized niches in the bone marrow $^{50}$.

\section{BLIMP1 IS A TUMOUR SUPPRESSOR GENE}

The region encompassing the $P R D M 1$ gene $(6 \mathrm{q} 21-$ $\mathrm{q} 22.1$ ) is frequently deleted in B cell lymphomas ${ }^{51,52}$. Inactivation of the PRDM1 gene was found in a subset of diffuse large $B$ cell lymphoma (DLBCL) of the activated $\mathrm{B}$-cell type $(\mathrm{ABC})$ and is believed to contribute to lymphomagenesis by blocking post-GC B cell differentiation $^{53-55}$. Although PRDM1 mutations occur in only $25 \%$ of ABC-DLBCL biopsies; the majority of other cases of this subtype lack BLIMP1 protein, suggesting that additional mechanisms may inhibit BLIMP1 translation or stability $^{54}$. For example, a role for the microRNA let-7 family in mediating the translational down-regulation of BLIMP1 in DLBCL has been proposed ${ }^{56}$. Alternatively, reciprocal translocations resulting in aberrant expression of BCL6 could contribute to the pathogenesis of DLBCL (ref. ${ }^{54}$ ). The malignant Hodgkin/Reed-Sternberg (HRS) cells of classical Hodgkin lymphoma (cHL) have BLIMP1 mRNA (ref. ${ }^{57}$ ). However, several studies show that in most cases BLIMP1 protein is only weakly expressed by HRS cells $^{57-60}$. This could indicate that plasma cell differentiation is initiated in a fraction of HRS cells but remains abortive $^{58}$. The absence of BLIMP1 protein in HRS cells could be due to the overexpression of miR-9 and let-7a miRNA (ref. ${ }^{61}$ ). The malignant lymphoplasmacytic cells found in patients with Waldenstrom's macroglobulinemia also express lower levels of BLIMP1 compared to normal plasma cells $^{62}$. Deleterious mutations of PRDMI associated with loss of BLIMP1 protein have also been reported in primary central nervous system lymphoma ${ }^{63}$. Finally, ETS-1, the transcription factor, which is amplified in certain leukemias, interacts with BLIMP1 leading to a block in BLIMP1 DNA binding activity and a reduction in the ability of BLIMP1 to repress target genes ${ }^{64-68}$.

In contrast, the over-expression of the BLIMP1 $\beta$ isoform has been reported in multiple myeloma, DLBCL and in some $\mathrm{T}$ cell lymphomas ${ }^{6,69-71}$. BLIMP1 $\beta$ over-expression is associated with advanced Ann Arbor stage and a high-risk International Prognostic Index in $\mathrm{T}$ cell lymphomas and with a shorter patient survival in both DLBCL and T cell lymphoma patients ${ }^{70,71}$. In both B and T cell lymphomas, BLIMP1 $\beta$ expression is also associated with in vitro resistance to chemotherapeutic agents ${ }^{70,71}$. Interestingly, the up-regulation of the BLIMP $1 \beta$ isoform in $\mathrm{T}$ cell lymphomas was associated with high C-MYC levels ${ }^{71}$. A recent study by Zhang et al. demonstrated that the up-regulation of the PRDM1 $\beta$ isoform was associated with hypomethylation of the PRDM $1 \beta$ specific promoter in a subset of DLBCL with aggressive behaviour ${ }^{72}$.

\section{REGULATION OF BLIMP1 BY THE EPSTEIN-BARR VIRUS}

Recently, we have shown that BLIMP $1 \alpha$ is down-regulated in primary human germinal centre (GC) B cells following expression of the Epstein-Barr virus (EBV) oncogene, latent membrane protein (LMP1) (ref. ${ }^{73}$ ). This is important because EBV is found in a substantial fraction of GC-derived lymphomas, including Hodgkin's lymphoma (HL), Burkitt's lymphoma (BL) and in a subset of DLBCL (ref. ${ }^{74}$ ). We also showed that the re-expression of BLIMP1a in EBV-infected B cells induced the virus lytic cycle, an event which can ultimately lead to virus replication and cell death. Our observations suggest that the loss of BLIMP1 $\alpha$ expression could contribute to EBVinduced lymphomagenesis not only by suppressing plasma cell differentiation by also by preventing induction of the viral lytic cycle.

Although we have shown that EBV can down-regulate BLIMP1, it is not known if BLIMP1 $\alpha$ is involved in the early stages of B cell immortalization and consequently in 


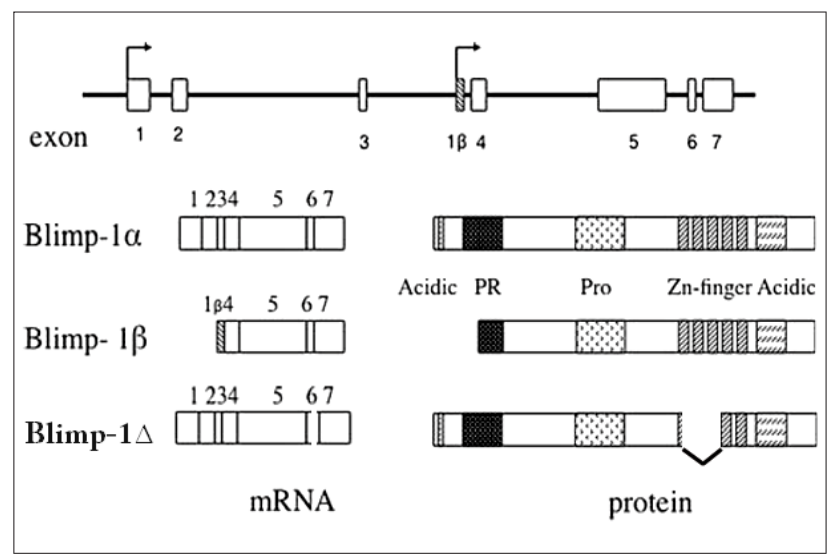

Fig. 1. Schematic of the genomic structure and $\alpha, \beta$ and $\Delta$ mRNAs of human BLIMP1. BLIMP1 $\beta$ lacks the first 3 exons and the amino-terminal 101 amino acids of BLIMP $1 \alpha$ and has a new exon, $1 \beta$. BLIMP $1 \beta$ transcripts initiate from an alternative promoter between exons 3 and 4 . Numbered open boxes represent the exons. BLIMP $1 \Delta 6$ lacks exon 6 and the first 3 zinc fingers (modified from Hangaishi and Kurokawa, 2010) $\left(\right.$ (ref. $^{75}$ )

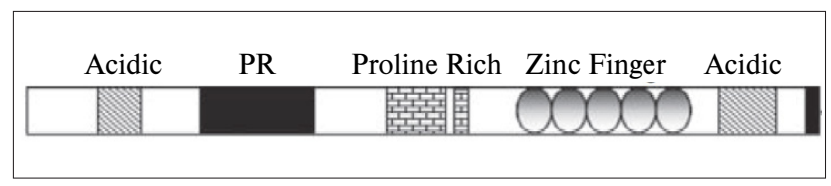

Fig. 2. Domain structures of BLIMP1. The BLIMP1 protein harbors five zinc fingers involved in DNA binding and proteinprotein interactions, two acidic regions, a PR domain and a proline rich region (modified from John and Garrett-Sinha, 2009) $\left(\right.$ ref. $\left.^{76}\right)$.

the establishment of primary infection. In preliminary experiments, we have shown that the infection of peripheral blood B cells with EBV is followed in the first few days of infection by the transient up-regulation of BLIMP1 $\alpha$ mRNA which is followed soon after by its down-regulation (Vrzalikova et al. unpublished observations). It is tempting to speculate that the up-regulation of BLIMP $1 \alpha$ in newly infected $B$ cells might contribute to the induction of the viral lytic cycle which has been shown to be important for efficient EBV-induced transformation.

Our microarray studies have revealed that while the transcriptional programs of LMP1 and BLIMP $1 \alpha$ show a surprising overlap, an important subset of genes are repressed by BLIMP $1 \alpha$ but induced by LMP1. These included $C-M Y C$, the suppression of which is essential for plasma cell differentiation. We have proposed that LMP1 drives a reciprocal regulatory loop involving BLIMP1 $\alpha$ and C-MYC, which ultimately leads to the activation of C-MYC and the repression of BLIMP $1 \alpha$. Taken together our findings suggest that while LMP1 might be capable of driving post-GC B-cell differentiation, it appears to disrupt plasma cell differentiation. Our model has implications for the treatment of EBV-associated lymphomas since small molecule inhibitors of C-MYC might be expected to induce BLIMP $1 \alpha$ expression potentially resulting in differentiation and cell cycle exit.

\section{ABBREVIATIONS}

ABC-DLBCL, Diffuse large B cell lymphoma of the activated B-cell type; BCL2A1, BCL2 family member A1; BLIMP1, B lymphocyte induced maturation protein 1; cHL, Classical Hodgkin lymphoma; EBV, EpsteinBarr virus; GCs; Germinal centres; HDACs, Histone deacetylases; HMT, Histone methyl transferases; HRS, Hodgkin/Reed-Sternberg; IRF, IFN regulatory factor; Ig, Immunoglubulin; LMP1, Latent membrane protein; NFAT, Nuclear factor of activated T cells; PAX5, Paired box gene 5; PRDI, Positive regulatory domain I; PRDIBF1, Positive regulatory domain I-binding factor 1; XBP1, X-box binding protein 1 .

\section{ACKNOWLEDGEMENT}

This work was supported by the Leukaemia and Lymphoma Research Fund, in part by European Union (infrastructure support CZ.1.05/2.1.00/01.0030 and CZ.1.07/2.3.00/20.0019).

\section{REFERENCES}

1. Keller AD, Maniatis T. Identification and characterization of a novel repressor of beta-interferon gene expression. Genes Dev 1991;5:8689.

2. Turner CA Jr, Mack DH, Davis MM. Blimp-1, a novel zinc finger-containing protein that can drive the maturation of $B$ lymphocytes into immunoglobulin secreting cells. Cell 1994;77:297-306.

3. Blackman MA, Tigges MA, Minie ME, Koshland ME. A model system for peptide hormone action in differentiation:interleukin 2 induces a B lymphoma to transcribe the J chain gene. Cell 1986;46:609-17.

4. Shapiro-Shelef M, Lin KI, McHeyzer-Williams LJ, Liao J, McHeyzerWilliams MG, Calame K. Blimp-1 is required for the formation of immunoglobulin secreting plasma cells and pre-plasma memory B cells. Immunity 2003;19:607-20.

5. Mock BA, Liu L, LePaslier D, Huang S. The B-lymphocyte maturation promoting transcription factor BLIMP1/PRDI-BF1 maps to D6S447 on human chromosome $6 q 21-q 22.1$ and the syntenic region of mouse chromosome 10. Genomics 1996; 37:24-8.

6. Györy I, Fejér G, Ghosh N, Seto E, Wright KL. Identification of a functionally impaired positive regulatory domain I binding factor 1 transcription repressor in myeloma cell lines. J Immunol 2003;170:125-33.

7. Calame KL, Lin KI, Tunyaplin C. Regulatory mechanisms that determine the development and function of plasma cells. Annu Rev Immunol 2003;21:205-30.

8. Tunyaplin C, Shapiro MA, Calame KL. Characterization of the B lymphocyte induced maturation protein-1 (Blimp-1) gene, mRNA isoforms and basal promoter. Nucleic Acids Res 2000;28:4846-55.

9. Schmidt D, Nayak A, Schumann JE, Schimpl A, Berberich I, BerberichSiebelt F. Blimp-1Deltaexon7: a naturally occurring Blimp-1 deletion mutant with auto-regulatory potential. Exp Cell Res 2008;314:361427.

10. Smith MA, Maurin M, Cho HI, Becknell B, Freud AG, Yu J, Wei S, Djeu J, Celis E, Caligiuri MA, Wright KL. PRDM1/Blimp-1 controls effector cytokine production in human NK cells. J Immunol 2010;185:605867.

11. Huang S, Shao G, Liu L. The PR domain of the Rb-binding zinc finger protein RIZ1 is a protein binding interface and is related to the SET domain functioning in chromatin-mediated gene expression. J Biol Chem 1998;273:15933-9.

12. Dillon SC, Zhang X,Trievel RC, Cheng X. The SET-domain protein superfamily: protein lysine methyltransferases. Genome Biol 2005;6:227. 
13. Keller AD, Maniatis T. Only two of the five zinc fingers of the eukaryotic transcriptional repressor PRDI-BF1 are required for sequencespecific DNA binding. Mol Cell Biol 1992;12:1940-9.

14. Kuo TC, Calame KL. B lymphocyte-induced maturation protein (Blimp)-1, IFN regulatory factor (IRF)-1, and IRF-2 can bind to the same regulatory sites. J Immunol 2004;173:5556-63.

15. Ren B, Chee KJ, Kim TH, Maniatis T. PRDI-BF1/Blimp-1 repression is mediated by corepressors of the Groucho family of proteins. Genes Dev 1999;13:125-37.

16. Györy I, Wu J, Fejér G, Seto $E$, Wright KL. PRDI-BF1 recruits the histone $\mathrm{H} 3$ methyltransferase G9a in transcriptional silencing. Nat Immuno 2005;5:299-308.

17. Yu J, Angelin-Duclos C, Greenwood J, Liao J, Calame K. Transcriptiona repression by Blimp-1 (PRDI-BF1) involves recruitment of histone deacetylase. Mol Cell Biol 2000;20:2592-603.

18. Su ST, Ying HY, Chiu YK, Lin FR, Chen MY, Lin KI. Involvement of his tone demethylase LSD1 in Blimp-1-mediated gene repression during plasma cell differentiation. Mol Cell Biol 2009;29:1421-31.

19. Shi Y, Lan F, Matson C, Mulligan P, Whetstine JR, Cole PA, Casero RA Shi Y. Histone demethylation mediated by the nuclear amine oxidase homolog LSD1. Cell 2004;119:941-53.

20. Savitsky D, Calame K. B-1 B lymphocytes require Blimp-1 for immunoglobulin secretion. J Exp Med 2006;203:2305-14.

21. Schliephake DE, Schimpl A. Blimp-1 overcomes the block in IgM secretion in lipopolysaccharide/antimu $F\left(a b^{\prime}\right) 2$-costimulated B lymphocytes. Eur J Immunol 1996;26:268-71.

22. Kallies A, Hasbold J, Fairfax K, Pridans C, Emslie D, McKenzie BS, Lew AM, Corcoran LM, Hodgkin PD, Tarlinton DM, Nutt SL. Initiation of plasma-cell differentiation is independent of the transcription factor Blimp-1. Immunity 2007;26:555-66.

23. Cobaleda C, Schebesta A, Delogu A, Busslinger M. Pax5: the guardian of B cell identity and function. Nat Immunol 2007;8:463-70.

24. Reimold AM, Iwakoshi NN, Manis J, Vallabhajosyula P, SzomolanyiTsuda E, Gravallese EM, Friend D, Grusby MJ, Alt F, Glimcher LH. Plasma cell differentiation requires the transcription factor XBP-1. Nature 2001;412:300-7.

25. Calfon M, Zeng H, Urano F, Till JH, Hubbard SR, Harding HP, Clark SG, Ron D. IRE1 couples endoplasmic reticulum load to secretory capacity by processing the XBP-1 mRNA. Nature 2002;415:92-96.

26. Shaffer AL, Shapiro-Shelef M, Iwakoshi NN, Lee AH, Qian SB, Zhao H, Yu X, Yang L, Tan BK, Rosenwald A, Hurt EM, Petroulakis E, Sonenberg N, Yewdell JW, Calame K, Glimcher LH, Staudt LM. XBP1, downstream of Blimp-1, expands the secretory apparatus and other organelles, and increases protein synthesis in plasma cell differentiation. Immunity 2004;21:81-93.

27. Kallies A, Hasbold J, Tarlinton DM, Dietrich W, Corcoran LM, Hodgkin PD, Nutt SL. Plasma cell ontogeny defined by quantitative changes in blimp-1 expression. J Exp Med 2004;200:967-77.

28. Messika EJ, Lu PS, Sung YJ, Yao T, Chi JT, Chien YH, Davis MM. Differential effect of $B$ lymphocyte-induced maturation protein (Blimp-1) expression on cell fate during B cell development. J Exp Med 1998;188:515-25.

29. Klein U, Casola S, Cattoretti G, Shen Q, Lia M, Mo T, Ludwig T, Rajewsky K, Dalla-Favera R. IRF4 controls plasma cell differentiation and class switch recombination. Nature Immunol 2006;7:773-82.

30. Sciammas R, Shaffer AL, Schatz JH, Zhao H, Staudt LM, Singh H. Graded expression of interferon regulatory factor-4 coordinates isotype switching with plasma cell differentiation. Immunity 2006;25:225-36.

31. Grumont RJ, Gerondakis S. Rel induces interferon regulatory factor 4 (IRF-4) expression in lymphocytes: modulation of interferonregulated gene expression by rel/nuclear factor kappaB. J Exp Med 2000;191:1281-92.

32. Lalmanach-Girard AC, Chiles TC, Parker DC, Rothstein TL. T cell-dependent induction of NF-kappa B in B cells. J Exp Med 1993;177:1215-19.

33. Berberich I, Shu GL, Clark EA. Cross-linking CD40 on B cells rapidly activates nuclear factor-kappa B. J Immunol 1994;153:4357-66.

34. Winslow MM, Gallo EM, Neilson JR, Crabtree GR. The calcineurin phosphatase complex modulates immunogenic $B$ cell responses. Immunity 2006:24:141-52.

35. Shaffer AL, Lin KI, Kuo TC, Yu X, Hurt EM, Rosenwald A, Giltnane JM Yang L, Zhao H, Calame K, Staudt LM. Blimp-1 orchestrates plasma cell differentiation by extinguishing the mature $B$ cell gene expression program. Immunity 2002;17:51-62.

36. Sciammas R, Davis MM. Modular nature of Blimp-1 in the regulation of gene expression during $B$ cell maturation. J Immunol 2004;172:5427-40.

37. Manis JP, Gu Y, Lansford R, Sonoda E, Ferrini R, Davidson L, Rajewsky K, Alt FW. Ku70 is required for late B cell development and immunoglobulin heavy chain class switching. J Exp Med 1998;187:2081-89.

38. Muramatsu M, Kinoshita K, Fagarasan S, Yamada S, Shinkai Y, Honjo T. Class switch recombination and hypermutation require activationinduced cytidine deaminase (AID), a potential RNA editing enzyme. Cell 2000;102:553-63.

39. Zelazowski P, Max EE, Kehry MR, Snapper CM. Regulation of Ku expression in normal murine $B$ cells by stimuli that promote switch recombination. J Immunol 1997;159:2559-62.

40. Piskurich JF, Lin KI, Lin Y, Wang Y, Ting JP, Calame K. BLIMP-I mediates extinction of major histocompatibility class II transactivator expression in plasma cells. Nat Immunol 2000;1:526-32.

41. Silacci P, Mottet A, Steimle V, Reith W, Mach B. Developmental extinction of major histocompatibility complex class II gene expression in plasmocytes is mediated by silencing of the transactivator gene CIITA. J Exp Med 1994;180:1329-36.

42. Lin $Y$, Wong $K$, Calame K. Repression of c-myc transcription by Blimp-1, an inducer of terminal B cell differentiation. Science 1997;276:596-9.

43. Coller HA, Grandori C, Tamayo P, Colbert T, Lander ES, Eisenman RN, Golub TR. Expression analysis with oligonucleotide microarrays reveals that MYC regulates genes involved in growth, cell cycle, signaling, and adhesion. Proc Natl Acad Sci U S A 2000;97:3260-5.

44. Eilers M. Control of cell proliferation by Myc family genes. Mol Cells 1999;9:1-6.

45. Lin KI, Lin Y, Calame K. Repression of c-myc is necessary but not sufficient for terminal differentiation of $B$ lymphocytes in vitro. Mol Cell Biol 2000;20:8684-95.

46. Knödel M, Kuss AW, Lindemann D, Berberich I, Schimpl A. Reversal of Blimp-1-mediated apoptosis by A1, a member of the Bcl-2 family. Eur J Immunol 1999;29:2988-98.

47. Lin KI, Angelin-Duclos C, Kuo TC, Calame K. Blimp-1-dependent repression of Pax-5 is required for differentiation of B cells to immunoglobulin M-secreting plasma cells. Mol Cell Biol 2002;22:4771-80.

48. Rinkenberger JL, Wallin JJ, Johnson KW, Koshland ME. An interleukin-2 signal relieves BSAP (Pax5)-mediated repression of the immunoglobulin J chain gene. Immunity 1996;5:377-86.

49. Singh $M$, Birshtein BK. NF-HB (BSAP) is a repressor of the murine immunoglobulin heavy-chain 3' alpha enhancer at early stages of B-cell differentiation. Mol Cell Biol 1993;13:3611-22.

50. Kabashima K, Haynes NM, Xu Y, Nutt SL, Allende ML, Proia RL, Cyster JG. Plasma cell S1P1 expression determines secondary lymphoid organ retention versus bone marrow tropism. J Exp Med 2006;203:2683-90.

51. Jackson A, Carrara P, Duke V, Sinclair P, Papaioannou M, Harrison CJ, Foroni L. Deletion of 6q16-q21 in human lymphoid malignancies: a mapping and deletion analysis. Cancer Res 2000;60:2775-9.

52. Thelander EF, Ichimura K, Corcoran M, Barbany G, Nordgren A Heyman M, Berglund M, Mungall A, Rosenquist R, Collins VP, Grandér $D$, Larsson C, Lagercrantz S. Characterization of $6 q$ deletions in mature B cell lymphomas and childhood acute lymphoblastic leukemia. Leuk Lymphoma 2008:49:477-87.

53. Tam W, Gomez M, Chadburn A, Lee JW, Chan WC, Knowles DM. Mutational analysis of PRDM1 indicates a tumor-suppressor role in diffuse large B-cell lymphomas Blood 2006;107:4090-4100.

54. Pasqualucci L, Compagno M, Houldsworth J, Monti S, Grunn A, Nandula SV, Aster JC, Murty VV, Shipp MA, Dalla-Favera R. Inactivation of the PRDM1/BLIMP1 gene in diffuse large $B$ cell lymphoma. J Exp Med 2006;203:311-7.

55. Mandelbaum J, Bhagat G, Tang H, Mo T, Brahmachary M, Shen Q, Chadburn A, Rajewsky K, Tarakhovsky A, Pasqualucci L, DallaFavera R. BLIMP1 is a tumor suppressor gene frequently disrupted in activated B cell-like diffuse large B cell lymphoma. Cancer Cell 2010;18:568-79.

56. Nie K, Zhang T, Allawi H, Gomez M, Liu Y, Chadburn A, Wang YL, Knowles DM, Tam W. Epigenetic down-regulation of the tumor suppressor gene PRDM1/Blimp-1 in diffuse large B cell lymphomas: a potential role of the microRNA let-7. Am J Pathol 2010;177:1470-9. 
57. Garcia JF, Roncador G, García JF, Sánz Al, Maestre L, Lucas E, MontesMoreno S, Fernandez Victoria R, Martinez-Torrecuadrara JL, Marafioti T, Mason DY, Piris MA. PRDM1/BLIMP-1 expression in multiple B and T-cell lymphoma. Haematologica 2006;91:467-74.

58. Buettner M, Greiner A, Avramidou A, Jäck HM, Niedobitek G. Evidence of abortive plasma cell differentiation in Hodgkin and Reed-Sternberg cells of classical Hodgkin lymphoma. Hematol Oncol 2005;23:127-132.

59. Cattoretti G, Angelin-Duclos C, Shaknovich R, Zhou H, Wang D Alobeid B. PRDM1/Blimp-1 is expressed in human B-lymphocytes committed to the plasma cell lineage. J Pathol 2005;206:76-86.

60. Natkunam Y, Hsi ED, Aoun P, Zhao S, Elson P, Pohlman B, Naushad H, Bast M, Levy R, Lossos IS. Expression of the human germinal centerassociated lymphoma (HGAL) protein identifies a subset of classic Hodgkin lymphoma of germinal center derivation and improved survival. Blood 2007;109:298-305.

61. Nie K, Gomez M, Landgraf P, Garcia JF, Liu Y, Tan LH, Chadburn A, Tuschl T, Knowles DM, Tam W. MicroRNA-mediated down-regulation of PRDM1/Blimp-1 in Hodgkin/Reed-Sternberg cells: a po tential pathogenetic lesion in Hodgkin lymphomas. Am J Patho 2008;173:242-52.

62. Gutiérrez NC, Ocio EM, de Las Rivas J, Maiso P, Delgado M, Fermiñán E, Arcos MJ, Sánchez ML, Hernández JM, San Miguel JF. Gene expression profiling of B lymphocytes and plasma cells from Waldenström's macroglobulinemia: comparison with expression patterns of the same cell counterparts from chronic lymphocytic leukemia, multiple myeloma and normal individuals. Leukemia 2007;21:541-9.

63. Courts $C$, Montesinos-Rongen M, Brunn A, Bug S, Siemer D, Hans V, Blümcke I, Klapper W, Schaller C, Wiestler OD, Küppers R, Siebert $R$, Deckert M. Recurrent inactivation of the PRDM1 gene in primary central nervous system lymphoma. J Neuropathol Exp Neuro 2008;67:720-7.

64. Rovigatti U, Watson DK, Yunis JJ. Amplification and rearrangement of Hu-ets-1 in leukemia and lymphoma with involvement of 11q23. Science 1968 232:398-400.

65. Crossen PE, Morrison MJ, Rodley P, Cochrane J, Morris CM. Identification of amplified genes in a patient with acute myeloid leukemia and double minute chromosomes. Cancer Genet Cytogenet 1999;113:126-33.

66. Yoshida T, Kimura N, Akiyoshi T, Ohshima K, Nagano M, Morioka E, Hisano S, Ohyashiki K, Kamada N, Tamura K. Jumping translocation of homogeneously staining region and tetraploidy with double min- utes in acute myelomonocytic leukemia. Cancer Genet Cytogenet 1999;109:40-4

67. Sait SN, Qadir MU, Conroy JM, Matsui S, Nowak NJ, Baer MR. Double minute chromosomes in acute myeloid leukemia and myelodysplastic syndrome: identification of new amplification regions by fluorescence in situ hybridization and spectral karyotyping. Genes Chromosomes Cancer 2002;34:42-7.

68. John SA, Clements JL, Russell LM, Garrett-Sinha LA. Ets-1 regulates plasma cell differentiation by interfering with the activity of the transcription factor Blimp-1. J Biol Chem 2007;283:951-62.

69. Ocaña E, González-García I, Gutiérrez NC, Mora-López F, Brieva JA, Campos-Caro A. The expression of PRDI-BF1 beta isoform in multiple myeloma plasma cells. Haematologica 2006;91:1579-80.

70. Liu YY, Leboeuf C, Shi JY, Li JM, Wang L, Shen Y, Garcia JF, Shen ZX, Chen Z, Janin A, Chen SJ, Zhao WL. Rituximab plus CHOP (R-CHOP) overcomes PRDM1-associated resistance to chemotherapy in patients with diffuse large B-cell lymphoma. Blood 2007;1 10:339-44.

71. Zhao WL, Liu YY, Zhang QL, Wang L, Leboeuf C, Zhang YW, Ma J, Garcia JF, Song YP, Li JM, Shen ZX, Chen Z, Janin A, Chen SJ. PRDM1 is involved in chemoresistance of T-cell lymphoma and down-regulated by the proteasome inhibitor. Blood 2008;111:3867-71.

72. Zhang YW, Xie HQ, Chen Y, Jiao B, Shen ZX, Chen SJ, Zhao WL. Loss of promoter methylation contributes to the expression of functionally impaired PRDM1 $\beta$ isoform in diffuse large B-cell lymphoma. Int J Hematol 2010;92:439-44

73. Vrzalikova K, Vockerodt M, Leonard S, Bell A, Wei W, Schrader A, Wright $K L$, Kube $D$, Rowe $M$, Woodman CB, Murray PG. Downregulation of BLIMP1-alpha by the EBV oncogene, LMP1, disrupts the plasma cell differentiation program and prevents viral replication in B cells: implications for the pathogenesis of EBVassociated B cell lymphomas Blood 2011;117:5907-17.

74. Park S, Lee J, Ko YH, Han A, Jun HJ, Lee SC, Hwang IG, Park YH, Ahn JS, Jung CW, Kim K, Ahn YC, Kang WK, Park K, Kim WS.The impact of Epstein-Barr virus status on clinical outcome in diffuse large B-cell lymphoma. Blood 2007;110:972-8.

75. Hangaishi A, Kurokawa M. Blimp-1 is a tumor suppressor gene in lymphoid malignancies. Int J Hematol 2010;91:46-53.

76. John SA, Garrett-Sinha LA. Blimp1: a conserved transcriptional repressor critical for differentiation of many tissues. Exp Cell Res 2009;315:1077-84. 